\title{
INCLUSÃO PRODUTIVA, POLÍTICAS PÚBLICAS E EMPODERAMENTO DAS MULHERES AGRICULTORAS FAMILIARES DE PARAIPABA - CE ${ }^{1}$
}

\author{
Productive inclusion, public policies and empowerment of family farmers of Paraipaba \\ $-C E$
}

\author{
Virzângela Paula Sandy Mendes ${ }^{2}$ \\ Helenira Elery Marinho ${ }^{3}$ \\ Antonio George Lopes Paulino ${ }^{4}$
}

RESUMO: O presente artigo faz uma análise sócio antropológica sobre a experiência de um Grupo de Produção de Mulheres de Paraipaba, CE, que, estimuladas por ações afirmativas de gênero participaram do PAA e do PNAE, cuja Lei no 11.947 determina que no mínimo 30\% do valor repassado da compra de alimentos destine-se à agricultura familiar. Os resultados apontam que as mulheres conquistaram relativo reconhecimento da família e da comunidade a partir de sua inclusão produtiva, que as tornou responsáveis por parte das despesas da casa. Por outro lado, as questões políticas e burocracias das instituições apontam que a autonomia desses agentes deve ser assegurada a partir da construção social de mercados alternativos.

Palavras-chaves: Agricultura familiar, políticas públicas, relações de gênero.

ABSTRACT: The present article analyzes socio-anthropological analysis of the experience of a Women's Production Group of Paraipaba, CE, which, stimulated by affirmative actions of gender, participated in the PAA and PNAE, Law No. 11,947 determining that at least $30 \%$ of the value of food purchases is for family farming. The results indicate that women have achieved relative recognition of the family and the community from their productive inclusion, which made them responsible for part of the household expenses. On the other hand, the political issues and bureaucracies of the institutions point out that the autonomy of these agents must be ensured from the social construction of alternative markets.

Key-words: Family agriculture, public policies, gender relations.

1 Parte das discussões aqui trazidas foram apresentadas no GT 08 (Políticas e Intervenção do Estado na Agricultura Familiar e na Segurança Alimentar e Nutricional) do VII Encontro da Rede de Estudos Rurais "Olhares conflitantes sobre o mundo rural: territorialidades, conhecimentos e ações de desenvolvimento", em 2016.

${ }^{2}$ Assistente Social, Mestre em políticas públicas e Doutora em sociologia pela Universidade Federal do Ceará. Professora do curso de Serviço Social da Faculdade Ratio e Faculdade Cearense. E-mail: virzangelamendes@gmail.com

3 Engenheira agrônoma, Doutora em Sociologia pela Universidade Federal do Ceará e Pesquisadora da EMBRAPA. E-mail: helenira.vasconcelos@embrapa.br

4 Doutor em Sociologia pela Universidade Federal do Ceará, Docente da Universidade Federal do Ceará. E-mail: antoniogeorge lopespaulino@yahoo.com.br 


\section{INTRODUÇÃO}

As políticas públicas voltadas para o desenvolvimento rural ganharam nova roupagem a partir de 1995 . As unidades de produção familiar passaram a ser 0 ponto focal nas estratégias do desenvolvimento econômico. Em decorrência, a noção de desenvolvimento agrícola ganhou amplidão. Desapareceu o caráter estritamente agrícola ganhando força as várias dimensões dos espaços rurais. $O$ limitado conceito de "pequena produção" foi esvaziado e transformado na robusta denominação de "agricultura familiar", no bojo do surgimento do Programa Nacional de Fortalecimento da Agricultura Familiar - PRONAF.

Apoiando os projetos estruturantes do PRONAF, proliferaram vários programas complementares, bem como diversificadas ações afirmativas em meio aos espaços rurais. Tais políticas tiveram uma maior amplitude a partir do Governo Lula, momento marcado pela criação do Ministério do Desenvolvimento Agrário (MDA) e a criação da Lei 11.326, de julho de 2006, que define os seguintes requisitos para a classificação de agricultor familiar:

I - não detenha, a qualquer título, área maior do que 4 (quatro) módulos fiscais; II - utilize predominantemente mão de obra da própria família nas atividades econômicas do seu estabelecimento ou empreendimento; III - tenha renda familiar predominantemente originada de atividades econômicas vinculadas ao próprio estabelecimento ou empreendimento; IV - dirija seu estabelecimento ou empreendimento com sua família.

Nesse contexto, citamos como exemplo o Programa de Aquisição de Alimentos (PAA), criado em 2003, o qual exige que 40\% dos agricultores cadastrados sejam mulheres. Esta determinação vem incentivando o chamado "protagonismo de mulheres agricultoras familiares", cujo trabalho e participação na geração da renda familiar eram e continuam sendo, embora em menor proporção, pouco valorizados e até invisível.

Assim, a presente pesquisa tem como objetivo principal compreender o papel das mulheres nas unidades de produção familiar, enfocando as mudanças nas relações de gênero ${ }^{5}$ a partir da comercialização através do Programa de Aquisição

5 Os estudos de Brumer (2004) destacam que a categoria "gênero" relaciona-se a características socialmente construídas, atribuindo papéis diferentes aos homens e mulheres. Nesse sentido, tratase, para a autora, de uma construção simbólica, que confere determinadas designações às pessoas a partir do sexo. Ressalte-se, por outro lado, que o gênero vai além do simbólico; há dimensões materiais de construção e vivência do gênero, que se dá a nível cotidiano, que reitera o que hegemonicamente entende-se por lugares sociais designados às mulheres e aos homens. 
de Alimentos (PAA) e do Programa Nacional de Alimentação Escolar - PNAE. Interessa-nos compreender quais as principais mudanças em suas vidas a partir da comercialização dos seus produtos e de sua organização associativa.

A metodologia pautou-se por um estudo qualitativo, utilizando-se como estratégia a pesquisa bibliográfica e a pesquisa de campo, cujos principais instrumentos de coleta de dados foram a entrevista semiestruturada e a observação direta.

Para a exposição dos resultados dividimos este artigo em duas partes: na primeira apresentamos uma breve contextualização sobre o Perímetro CuruParaipaba através dos relatos de colonos e mulheres, fazendo um breve resgate histórico desde a sua implantação até os dias atuais. Esta contextualização nos parece necessária, pois este espaço rural $^{6}$ foi forjado a partir de uma intervenção estatal, a qual deliberou desde a seleção das pessoas até padrões de produção agrícola, comercialização e influências nas sociabilidades dos sujeitos ocupantes daquele espaço construído.

$\mathrm{Na}$ segunda parte trazemos um pouco da trajetória de agricultoras que decidiram se organizar em associação e coletivamente comercializam seus produtos para a merenda escolar via PAA e PNAE, programas governamentais que objetivam promover a comercialização de produtos dos agricultores familiares para a merenda escolar. Com isso, fortalecem a economia local, promovem a segurança alimentar e, no caso das mulheres, incentivam o seu protagonismo e autonomia.

\section{RELATOS DA HISTÓRIA DE COLONOS E MULHERES DO PERÍMETRO CURU-PARAIPABA}

O Perímetro Curu-Paraipaba foi implantado na década de 1970 a partir da intervenção estatal capitaneada pelo Departamento Nacional de Obras Contra as Secas - DNOCS. Inserido na proposta de modernização agrícola do Governo Militar, a ideia prioritária era, a partir da desapropriação de terras, implementar uma

\footnotetext{
6 Esta noção de espaço rural foi discutida por Wanderley (2009, p. 29), que o classifica enquanto [...] "singular espaço de vida, socialmente construído pelos seus habitantes, em função das relações fundadas nos laços de parentesco e de vizinhança, e isto, tanto ao nível da vida cotidiana, quando dos ritmos dos acontecimentos que determinam os ciclos da vida familiar, tais como, nascimentos, casamentos e mortes e, ainda, no que se refere ao calendário das manifestações de ordem cultural e religiosa".
} 
infraestrutura de irrigação que pudesse abastecer as agroindústrias com matériasprimas e mão de obra abundante e barata (MENDES, 2018; BURSZTYN, 2008; CARVALHO, 1987; DINIZ, 2002). Para tanto, cerca de quinhentas famílias foram assentadas nesta época. Estas famílias de agricultores, agora intituladas de colonos, deveriam se adaptar as regras estabelecidas pelo órgão. A fala a seguir (MENDES, 2018, p. 88) retrata como era a rotina dos colonos no início do Projeto:

Era só trabalho. Eu acordava duas horas da madrugada. Duas horas da madrugada eu já tava colocando a carroça no boi pra pegar capim. Quando chegava ia limpar o estábulo pra tirar o leite do gado. Quando dava de quatro horas em diante eu tirava o leite e levava pro posto [local da cooperativa em que os colonos levavam o leite]. Não tinha sossego não. Quando amanhecia passava o pé na bicicleta e ia pro lote. 11 horas ia pra casa pra almoçar. As duas e meia voltava de novo. Num dava tempo dar o cochilo não. O cochilim eu tô descontando agora [risos]. A gente trabalhava demais. Ali, se o cabra arranjasse alguma coisa era milionário. Aquilo foi feito no sistema que era só pro cabra trabalhar. A gente não tinha divertimento (EVAN, 69 anos).

Este relato conta também que era um tempo de intenso trabalho agrícola no Perímetro, destacando que os colonos eram monitorados pelos técnicos do DNOCS e que o Perímetro obedecia a uma lógica de funcionamento que intervia na dinâmica familiar, ou seja, os colonos faziam parte de uma imensa engrenagem, cheia de regras e atribuições. Os técnicos, inseridos em um contexto de matriz autoritária, reproduzia essa dimensão no cotidiano do Perímetro, marcado pelo exaustivo trabalho agrícola, conforme o relato a seguir (idem):

Eu: Porque vocês trabalhavam tanto?

Colono Sr. Evan: Porque era serviço demais. E tem mais. Ainda tinha uns fulano de tal técnico, uns agrônomo que não saia do lote da gente pastorando se o cabra tava no lote. O que ele tava fazendo, o que tinha pra fazer, o que tinha feito. Mas quando eu fui pra lá, eu já fui um cabra meio sabido, certas coisas eu cortava. Um dia chegou lá no lote um tal de Dr. Virgilio, não sei se a sra conheceu. Ele era irmão do Dr. Valter. Esse agrônomo era muito mais abusado que não sei o que e nesse tempo eu trabalhava. E tinha o que fazer e o recurso era pouco. Porque nesse tempo tinha a mão de obra que era quinze cruzeiro a diária. Essa mão de obra era pra tudo. Pra comprar tudo o que a gente precisava pra dentro de casa. Ai quando eu precisava pagar uma pessoa de fora pra trabalhar eu ainda tinha que botar três cruzeiros porque a diária era dezoito cruzeiro. Ai quando o cara tava por aqui de serviço o técnico ia lá e colocava dez diárias de quinze reais. Mas não era suficiente. A gente tinha que botar o restante. Porque a diária do cabra era dezoito e ele só botava de quinze. O negócio era arrochado. Era pra limpar a laranjeira, o 
capim, a cana. Era pra limpar tudo. Meu lote era uma parte de cana, tinha uma área de feijão e laranjeira e tinha o capim do gado. Antes da cana tinha a mandioca, o tomate. Depois vei o mamão. Quem definia as culturas era os técnicos era quem vinha e que dizia o que era pra gente plantar e a gente tinha que dar conta.

Eu: $E$ vocês podiam dizer que não queriam plantar?

Colono Sr. Evan: Não. Porque era tudo programado.

A dinâmica produtiva de cada lote era organizada a partir destas demandas externas protagonizadas pelos técnicos do DNOCS, que iam desde a definição das culturas a serem implantadas, a produção propriamente dita (plantio, adubação, pulverização, limpeza e colheita), até às formas de escoamento desta produção, que ia por meio de uma cooperativa gerenciada pelo DNOCS (MENDES, 2011).

Nesse contexto, as famílias assentadas, a maioria formada por antigos moradores, parceiros e arrendatários, passaram das relações patriarcais comandadas pelos fazendeiros para a tutela de um Estado autoritário e paternalista (BURSZTYN, 2008; DINIZ, 2002; MARTINS, 2008; OLIVEIRA, 1981).

Considerando esse cenário, apresento uma questão para análise: Qual o lugar das mulheres na trajetória deste Perímetro? Embora não tenhamos a pretensão de aprofundar esta questão tão complexa em poucas linhas, salientamos que, através dos relatos dos colonos, foi possível identificar que as mulheres sempre "ajudaram"7 no trabalho agrícola. Ou melhor, todos, filhos, filhas e a esposa participavam ativamente do trabalho agrícola, embora houvesse uma centralidade no colono, denominado como o chefe da família. O trabalho dos demais membros gravitava em torno das determinações autoritárias desta figura (MENDES, 2018, p. 116). Uma das agricultoras entrevistadas relatou:

[...] Tinha muita coisa pesada que a mulher num fazia. Por exemplo, quando o pai ia plantar o feijão nós [mulheres] num ia cavar. A gente ia plantar. Eles, os meninos, iam cavando na enxada e nós ia botando os três carocinhos de feijão na cova, milho era do mesmo jeito. Quando a gente ia plantar a roça eles iam cavando e o pai ia ensinando nós como plantar a mandioca, com o talozinho pra cima. A vó e a mãe ficavam em casa e iam fazer o almoço pra todo mundo. Tinha galinha, elas cuidavam das galinhas. Elas iam botar água pro gado.

7 Magalhães (2005) destacou em seus estudos que há uma divisão de tarefas na agricultura familiar, cabendo ao homem as atividades voltadas para a geração de renda e para as mulheres as tarefas reprodutivas e direcionadas ao autoconsumo. Desse modo, quando um dos dois atua fora de seu espaço de dominação, sua participação na execução da tarefa é tida como uma ajuda. Quando as mulheres são protagonistas nas atividades de geração de renda (no caso do PAA e PNAE), o trabalho do homem é considerado uma ajuda, como veremos neste texto. 
Estes relatos se alinham aos estudos de FISCHER (2005), que sinalizam um embricamento forte no meio rural entre as chamadas atividades produtivas (masculina) e reprodutivas (femininas), já que, geralmente, as mulheres participam dos espaços público e privado, embora este primeiro seja, historicamente, espaço de dominação masculina.

De outro lado, embora as mulheres participassem ativamente das atividades agrícolas, havia uma separação de papéis. Ou seja, no que se referia aos aspectos econômico-produtivo (produção, colheita, comercialização e participação nas reuniões da cooperativa para tratar sobre estes assuntos) cabia ao colono gerenciar, enquanto a parte dita social, desenvolvida por extensionistas e assistentes sociais, era direcionada às mulheres (MENDES, 2011). Fazia parte do repertório destas profissionais ensinar às mulheres a cuidar da casa, da alimentação e dos hábitos de higiene, conforme ilustrado nos relatos a seguir:

Tinha a Zulmira (extensionista) que era abusada. A gente fazia as coisa e ela pedindo que a gente fizesse mais, melhor. A gente barria o terrero e ela dizia que tinha que barrer por acolá tudo. Dizia que o coqueiro que tava perto tinha que limpá bem limpin. (Dona Almerinda, agricultora,78 anos).

Ela dava a ordem e tinha que fazer. Quem tava acostumada a zelar sua casa, limpar seus terreiros não sentiu dificuldade nenhuma. Mas a pessoa que não tinha esse costume, que vivia por aí a locel... Aí ela tinha que fazer. Quando ela dava uma ordem tinha que cumprir. (Nenzinha, agricultora, 77 anos).

Esta postura, conforme informações de funcionários do DNOCS, era necessária porque grande parte dos colonos eram pessoas "rústicas", com pouca instrução, carecendo, portanto, destas orientações aparentemente simples. É evidente, por outro lado, que havia certa negação da cultura trazida por estas famílias e a tentativa de implantar um padrão tido como adequado à nova condição de colono. Apesar de estas imposições serem acatadas na maioria das vezes, alguns colonos se indignavam com essa postura e resistiam. Um dos colonos relatou: "No dia que a D. Zuila veio pra medir o arroz e o óleo lá em casa eu disse: dona Zuila a senhora nunca trouxe aqui um quilo de arroz ou uma lata de óleo. Então pode voltar pra trás com essa conversa" (J. B., irrigante). 
É válido ressaltar que este modelo patriarcal ${ }^{8}$ centrado na autoridade do homem (aqui, no caso, o colono), era fortalecido e reiterado pela postura dos técnicos da autarquia, determinando que a casa é o lugar das mulheres casadas, enquanto a rua e os negócios é um lugar do masculino, do homem (DA MATTA, 1997). Esta postura conservadora e amplamente defendida pela ideologia dominante do período militar é revelada no relato de uma agricultora.

Um dia meu marido me chamou pra participar de uma reunião dos irrigantes e eu disse que só ia se ele fosse porque lá só tinha um magote de homem. Então eu fui, quando cheguei lá o Zé Francisco (gerente da cooperativa e funcionário do DNOCS) disse que a reunião é só para os irrigantes, e eu disse vou assistir a reunião e ai de quem me tirar daqui dessa cadeira, vou assistir a reunião, ouvir tudo e se precisar falar eu falo. Ele respondeu que eu além de tudo era linguaruda (Dona Mazé, agricultora, 54 anos).

A fala da agricultora relata um momento de enfrentamento aos costumes daquele contexto baseado no patriarcalismo. Assim, as relações de desigualdades de gênero nesse contexto se sustentam em estruturas do patriarcalismo, caracterizadas "pela autoridade, imposta institucionalmente, do homem sobre a mulher, que permeia todas as organizações da sociedade, da produção do consumo, à política, à legislação e à cultura" (CASTELLS, 1999, p. 169). O autor acrescenta ainda que esta estrutura conservadora se apresenta "no campo do discurso, da linguagem, da subjetividade e símbolos. Essas manifestações permeiam as relações sociais dentro e fora do espaço doméstico/privado" (CASTELLS, 1999, p. 169). Ou seja, embora ela fosse mulher e a ela estivesse determinado certo papel, ela ousou ocupar outro espaço, o espaço da rua, da esfera pública. Apesar desta ousadia, é oportuno destacar que foi o esposo quem a convidou, ou seja, o fato do marido respaldar a sua presença, de certa forma, pode ter impulsionado a mesma a tomar esta atitude de enfrentamento. Isto, contudo, não tira o seu mérito, especialmente considerando o cenário ditatorial da época.

8 Aqui me refiro ao patriarcalismo para entender as relações de gênero estabelecidas no Perímetro estudado, as quais eram naturalizadas e reafirmadas pelo poder institucional do DNOCS. Destacamos que no meio rural as relações estabelecidas entre os homens e mulheres são fortalecidas, portanto, pelos princípios do patriarcalismo que, para Saffioti (1987) trata-se de uma "construção social da superioridade masculina em detrimento da inferioridade e subordinação feminina, constituindo-se em um sistema sexual de poder que se hierarquiza na sociedade, na família, nas instituições e na divisão sexual do trabalho". 
Nesse contexto, entender o lugar da mulher no Perímetro Curu-Paraipaba é entender as relações de gênero que perpassam as sociabilidades destas famílias, quer seja no âmbito privado ou no público. Assim, segundo Scott (1991, p.14), "o gênero é um elemento constitutivo das relações sociais fundadas sobre as diferenças percebidas entre os sexos, o gênero é um primeiro modo de dar significado às relações de poder". Trata-se, portanto, de sociabilidades marcadas por relações de poder (FOUCAULT, 1979), em que estão imbricadas múltiplas relações de dominação entre gêneros. Nestas relações de dominação, o sujeito dominado poderá legitimar essa dominação pela sua incapacidade de apreendê-la, uma vez que esta faz parte de uma estrutura social que determina as relações sociais (BOURDIEU, 2003).

Esta delimitação de espaços, alinhada aos códigos de condutas dos governos militares (1964-1989), não conseguiu perdurar por muito tempo. Já no final da década de 1980, e, sobretudo, na década de 1990, os colonos foram "vendendo" 9 seus lotes, e seus filhos foram se casando, formando famílias e construindo suas moradias nas áreas de seus pais. Outras pessoas, ditas "de fora", foram chegando e construindo suas casas nas chamadas "áreas mortas", terras não irrigáveis, que poderiam ser classificadas hoje como Áreas de Preservação Ambiental (APA). Perímetro hoje engloba, não apenas atividades agropecuárias ${ }^{10}$, mas também as vinculadas ao turismo, ${ }^{11}$ quais sejam: os pequenos estabelecimentos comerciais, ou seja, restaurantes, cafés, barracas com comidas típicas e vendas de frutas, dentre outros.

Diante deste novo cenário cabe uma questão: A agricultura familiar deixou de ser uma prática característica deste espaço rural? Apesar da diversidade de atividades praticadas, predominam extensas fileiras de coqueirais no cenário do Perímetro, demonstrando o peso econômico desta atividade produtiva. Embora não caiba neste artigo uma discussão mais aprofundada sobre o atual modelo de

9 Colocamos vendendo entre aspas porque, legalmente, o dono é o DNOCS. Portanto, essas vendas são informais, embora registradas em cartório local.

10 Aqui englobo não apenas as atividades agropecuárias no âmbito familiar ou dos pequenos produtores e irrigantes, mas também as agroindústrias privadas.

11 Sobretudo após a construção da estrada do Sol Poente (CE-085), que corta o Perímetro e fornece acesso a todo o litoral oeste cearense, além da praia de Lagoinha, conhecida internacionalmente e vinculada às agências de turismo. Com destaque ainda para o Porto do Pecém. Trato sobre este aspecto na minha tese de doutorado. 
produção praticado no Perímetro, é possível afirmar que a pluratividade ${ }^{12}$ é uma marca destas famílias de agricultores. Além disso, registra-se nesse espaço rural a multiplicação e a diversidade de famílias, pois hoje não é mais só a família do colono que habita este espaço. Este fenômeno aponta para algumas mudanças, cabendo destacar: em decorrência do envelhecimento dos colonos e até do falecimento de alguns, os lotes originalmente explorados por uma única família (a do colono) ou foram repassados aos filhos ou foram vendidos, conforme já relatado.

Nesse sentido, aqueles que preferiram dividir o lote entre os herdeiros 0 fizeram a partir da divisão das carreiras de coqueiro, como explica a Nirinha, neta de colono e presidente da Associação das Mulheres Agricultoras Familiares de Paraipaba. Esta herdeira ainda relata que o seu avô (colono) "dividiu em vida" o lote com seus dez filhos, sendo que dois deles "são netos que foram criados como filhos". A sua avó (que hoje é viúva) é responsável pela divisão entre os sucessores dos parcos lucros advindos da comercialização do coco: "A vó faz assim. Quando o comprador tira o coco todo do lote ela recebe o dinheiro e divide com nós. É assim (risos)" (Nirinha, 35 anos). Vale acrescentar que no quintal tem a casa da avó, que mora com dois netos (sendo um de 25 anos que trabalha na comercialização do coco e outro de 23 anos que trabalha no Porto do Pecém), um tio e um irmão da Nirinha, os quais moram com suas famílias. A mãe dela "comprou um pedaço do quintal do vizinho, da casa 16, que fica do lado do nosso. No lote do meu avô mora eu com meu esposo que é agricultor e tem mais três casas que moram um irmão meu com a mulher dele e nas outras casas moram dois tios meus com suas famílias". Este exemplo sinaliza que, na busca de sustentabilidade, os agricultores buscam novas alternativas de geração de renda, sendo os programas governamentais (a exemplo do Bolsa Família, Benefício de Prestação Continuada BPC, Aposentadoria Rural, PAA e PNAE) de grande relevância para a complementação da renda familiar, inclusive um forte dinamizador do comércio local.

Nesse complexo mosaico de histórias e relatos destacamos nesse artigo a emergência de um grupo de mulheres que resolveram se organizar em associação

12 Sergio Schneider (2009) traz a perspectiva da pluriatividade para analisar as condições de vida dos agricultores familiares do Rio Grande do Sul. Assim como nossos estudos, ele aponta, dentre outros aspectos, que quanto maior o número de membros que exploram a mesma terra maio será a necessidade destas famílias se tornarem pluriativas. 
para se fortalecerem e buscarem melhores condições de vida a partir da comercialização de produtos para a merenda escolar via PNAE e PAA.

Vale frisar que, de acordo com Mutone-Smith (2011), existem duas maneiras de garantir às mulheres o acesso às novas oportunidades econômicas: usar a análise de gênero para ajudar a identificar aberturas e obstáculos e assegurar que as mulheres tenham voz para falar por elas mesmas. Falaremos sobre isto no próximo item deste artigo.

\section{RELATOS E VIVÊNCIAS DE UM GRUPO DE AGRICULTORAS DO PERÍMETRO CURU-PARAIPABA}

Os relatos anteriores sobre a constituição do Perímetro, a trajetória das famílias, os papéis de colono, mulheres e filhos, servem de pano de fundo para analisar os significados simbólicos e concretos relacionados à organização destas mulheres que, apesar de ainda embrionária, revela novas formas de empoderamento feminino naquele espaço rural.

A organização formal destas mulheres começou em 2010. Elas faziam parte de uma associação que comercializava os produtos através do Programa PAA (Programa de Aquisição de Alimentos), coordenado pela CONAB. Contudo, elas se queixavam da pouca autonomia frente às lideranças da entidade e também do fato dos titulares, em sua maioria, serem os maridos, colonos e/ou seus filhos.

Assim, a legislação específica do PNAE, Lei № 11.947, determina que no mínimo $30 \%$ do valor repassado da compra de alimentos se destinem diretamente à agricultura familiar. Já o PAA estabelece que a participação das mulheres deva ser considerada prioridade na seleção e execução de propostas, o que significou um incentivo maior para que estas mulheres se colocassem como protagonistas. Nesse sentido, citamos também a Resolução 44/2011, a qual assegura que, no mínimo, cinco por cento $(5 \%)$ da dotação orçamentária do PAA seja para as organizações de mulheres ou organizações mistas com participação mínima de setenta por cento (70\%) de mulheres em sua composição. Tudo isso, sem dúvida, representou um grande avanço.

Nesse contexto, algumas mulheres do Perímetro Curu-Paraipaba, esposas, viúvas, filhas e/ou netas de colonos se reuniram para formar uma associação. Elas pretendiam ampliar a renda familiar e, ao mesmo tempo, ultrapassarem as relações 
de poder no âmbito familiar que, historicamente, delimitaram o papel de homens e mulheres. O depoimento de uma mulher participante deste grupo nos chamou a atenção: "antes eu não tinha o meu dinheirinho e tudo que eu queria era o Ado (seu marido) quem comprava. Agora eu digo assim: taqui o dinheiro, vá lá e compre isso e aquilo" (Dona Iris, 56 anos).

O início da Associação aconteceu com cerca de 20 mulheres se reunindo e assessoradas por uma assistente social, ${ }^{13}$ funcionária da Associação dos Irrigantes $^{14}$, a qual ofereceu um curso de capacitação sobre associativismo. $O$ entusiasmo inicial as levou a organizarem a assembleia geral de constituição da entidade, a discutirem sobre o estatuto e a fazerem a eleição de sua primeira diretoria. Na ocasião, a agricultora Maria Silvanira Lourenço, a Nirinha, foi eleita presidente. Ao assumir este cargo, a vida da agricultora mudou completamente, ou melhor, ela passou a ocupar outros espaços, além da esfera do lar.

Eu já vendia meus bolos, mas era mais no final de semana. Eu levava aqui pra vender nas barracas do $\mathrm{D} 2^{15}$. Depois que eu assumi a presidência da associação das mulheres tive que sair muito de casa pra ir atrás das coisas. Pra registrar foi um sacrifício porque a gente precisou ajeitar a ata. Minha vida é participar de reunião. Participo das coisas da Igreja, mas também vou a reunião da Prefeitura, do Conselho de Segurança Alimentar, do Conselho Municipal de Assistência Social e até das reuniões do Território da Cidadania $^{16}$, lá em Itapipoca. Meu marido reclama. Ele diz essa mulher num para mais em casa! Mas eu não tô nem ai (risos) (Nirinha, 35 anos).

O relato da agricultora apresenta os trâmites burocráticos como um obstáculo, embora necessário para dar legitimidade legal ao grupo. Por outro lado, na medida em que o grupo de mulheres passou a ser reconhecido pela comunidade local, estas ocuparam espaços importantes em instâncias de controle social e, inclusive, em

13 Na época, eu, Virzângela Paula Sandy Mendes, havia concluído o mestrado em políticas públicas pela Universidade Estadual do Ceará e fazia parte da equipe técnica do Distrito.

14 Associação do Distrito de Irrigação Curu-Paraipaba (Distrito), entidade responsável pela administração operação e manutenção da infraestrutura de irrigação de uso comum do Perímetro e que, na época, também comercializava seus produtos para a merenda escolar via PAA/CONAB.

15 O Perímetro é dividido em oito setores: $B, C 1, C 2, D 1, D 2, E, G$ e H. O Setor D2 fica localizado às margens da Rodovia Estadual Estruturante $(\mathrm{Ce})$, local repleto de inúmeros comércios e passagem obrigatória de quem vai para o litoral Norte.

16 Ela faz referência ao Território da Cidadania dos Vales do Curu e Aracatiaçu, organização formada por 18 municípios e que se reúnem para discutir os problemas do Território, bem como as políticas públicas destinadas, sobretudo, aos agricultores familiares. O Programa de Desenvolvimento Territorial era coordenado pelo extinto Ministério do Desenvolvimento Agrário. 
palcos políticos em que se discute e se planeja as políticas públicas para o fortalecimento da agricultura familiar.

A agricultora, por outro lado, destaca que assumir suas funções de presidente exigiu firmar novos acordos no ambiente familiar, ou seja, ela precisou enfrentar a autoridade masculina, que exige que a mulher assuma atribuições concernentes ao cuidado da casa. Ela destaca ainda:

Eu fui até pra Brasília. Pra Marcha das Mulheres. Eu tenho aprendido muito. A gente precisa continuar organizada. Mas é tudo muito difícil. Eu me lembro que no começo elaboramos o projeto da CONAB. Muitas mulheres produziam polpa de frutas, mas havia muitas exigências. Tinha que ter um selo e a gente não tinha e era muito difícil conseguir. Demos muitas viagens em Fortaleza, lá na CONAB, mas no dia que saiu o projeto a gente tinha que mostrar o selo e ai não recebemos o dinheiro. Foi muito triste. Teve mulher que saiu do grupo porque achava que não ia dar certo.

É oportuno ressaltar que a história de organização das mulheres também registra lutas e dificuldades para acessar os programas governamentais. Este selo de qualidade é uma exigência para a comercialização de produtos processados, como a polpa de frutas. A dificuldade é resultado de vários fatores. De um lado, as mulheres não têm conhecimento sobre as normatizações, de outro lado não existem serviços de assistência técnica, tanto por parte do Estado, como do governo municipal. Isto acaba privilegiando os grandes.

A esse respeito, Nirinha acrescenta: "A gente procurou um produtor que tem uma agroindústria aqui. Mas ele disse que poderia vender os produtos dele e não 0 nosso. Outro pediu um valor tão alto que ia acabar com os nossos lucros". Desde 2014, cerca de oito mulheres da associação comercializam seus produtos através do PAA do município, executado pela Secretaria Municipal de Assistência Social. Elas informaram que "era para ser $\mathrm{R} \$ 6.500,00$ por ano para cada agricultora, mas não executaram o dinheiro todo". Não houve tempo. A tesoureira, por sua vez, relatou que o projeto todo era de $R \$ 128.000,00$ (cento e vinte e oito mil), mas só foram executados $R \$ 48.000,00$ (quarenta e oito mil), também por causa da escassez do tempo.

Embora desiludidas com a possibilidade de acesso ao PAA via CONAB, elas viram no PNAE uma possibilidade de atingir seus objetivos, ou seja, melhorar as condições de vida. Assim, em 2013 elas conseguiram o primeiro contrato para fornecer seus produtos para a merenda escolar. Nirinha ainda destaca: "Nós somos 
a única entidade do município de Paraipaba que está toda regular. Ainda mais que somos só de mulheres e todas tem a DAP (Declaração de Aptidão ao PRONAF)". O fato de estarem regulares com todas as certidões negativas de débitos junto ao FGTS, INSS, Receita Federal, Estadual e com o município foi decisivo para que elas participassem da chamada pública promovida pela Prefeitura. A tesoureira da entidade, a Sra. Kelliane enfatiza:

A gente paga $R \$ 250,00$ (duzentos e cinquenta reais) por mês pra uma contadora. Com muito gosto. Porque ela tem o trabalho de deixar a nossa associação toda regularizada pra gente poder concorrer na chamada pública da merenda. Nós só começamos a pagar quando a gente começou a receber o dinheiro da Prefeitura. $\mathrm{O}$ dinheiro não é muito, mas serve. Complementa a nossa renda.

Dessa forma, o grupo de mulheres vai conseguindo se manter adimplente com os órgãos públicos. Vale destacar que elas são imunes de impostos federais, estaduais e municipais. Depois de entregar os produtos nas escolas elas se dirigem até a Secretaria da Fazenda do Estado para a emissão de nota fiscal de venda de mercadorias e, com o documento em mãos e de posse das certidões negativas, procuram a Secretaria de Finanças para receber seus pagamentos. Elas informaram que há muitos problemas antes, durante de depois das chamadas públicas:

\begin{abstract}
A primeira demora é para elaborar a chamada pública. Nós só tivemos acesso a partir de 2013, com a posse do novo prefeito. Mas eles não sabiam de nada. Foi duro começar. Todo ano é assim, nunca começa no início das aulas e a gente sempre deixa de receber dinheiro porque o ano acabou e não pode ficar de um ano pro outro. Ano passado a gente começou a entregar em junho e depois de muita luta. Eu tive que levar as mulheres tudim pra sala do prefeito. Quem tava lá era o assessor dele. A gente disse que só ia sair de lá quando resolvesse. Ai ele disse: eita que ruma de mulheres valente! Somos mesmo, disse eu. (Nirinha)
\end{abstract}

Estas protelações ocorreram em função da morosidade dos órgãos públicos, da burocracia, mas também por questões políticas internas. As mulheres disseram que havia uma nutricionista que "era desenrolada", mas que teve que sair por causa de um desentendimento entre o marido dela e o prefeito. Sobre estas questões políticas a Nirinha ressalta que procura não se envolver: "eu quero saber é do recurso pra gente trabalhar". Para o ano de 2016, já houve a chamada pública e a entrega de seus produtos aconteceu no começo de abril: "ainda foi tarde. Mas foi melhor do que no ano passado" (Kelliane, 25 anos). 
Por outro lado, merece destaque nestas discussões os resultados do acesso ao PNAE para a vida destas mulheres. Alguns relatos são oportunos para esclarecer como o acesso à renda influencia na melhoria de condições de vida deste público. Vejamos:

Depois que eu comecei a participar do PNAE e do PAA minha vida melhorou. Eu antes fazia meus bolos numa batedeira bem pequeninha. Hoje minha batedeira é industrial. Meu forno cabe mais de 20 bolos de uma só vez. Sem contar que eu reformei minha casa. Ajeitei minha cozinha, fiz um alpendre. Às vezes a gente até se reúne aqui mesmo. Claro que meu marido ajudou. Ele me ajuda inclusive a bater o bolo, a mexer o doce. Um dia antes de entregar os produtos a gente trabalha junto porque eu num posso pagar uma pessoa. Tem que ser ele mesmo (risos) (Nirinha, 35 anos).

Eu e meu marido a gente trabalha junto. É ele quem leva os produtos pra entregar na escola. A gente também melhorou porque conseguimos comprar uma batedeira industrial, um liquidificador industrial, nosso forno é grande. É com esse dinheirinho que a gente vai colocando as coisas dentro de casa. É só eu e meu marido. Isso facilita também (Kelliane, 25 anos).

Meu filho pequeno me ajuda. Ele tem oito anos, mas já me ajuda a fazer as tapiocas. Ele raspa o coco. Com o dinheiro eu compro minhas coisas e pra ele também. $E$ ainda ajudo meu filho que estuda noutra cidade, que faz agronomia numa universidade federal (Neta, 40 anos).

Uma análise inicial das falas demonstra que as mulheres lograram êxito quanto à melhoria de seus instrumentos de trabalho, propiciando uma maior eficiência na produção e aumento da produtividade, sem considerar a ampliação da qualidade dos produtos. Uma análise mais atenta, por outro lado, demonstra alterações nos papéis de gênero no âmbito familiar, ou seja, os homens foram convocados a auxiliar no trabalho das mulheres.

Com isso, percebemos que para entregar os bolos, tapiocas, doces e biscoitos é necessário o envolvimento de ambos, homens e mulheres, promovendo uma relação mais solidária entre estes sujeitos. Nesse caso, o trabalho do homem surge como ajuda, conforme reflexão anterior. Isto não significa que os homens abandonaram sua função de provedor, apenas que este papel passou a ser dividido com a esposa. Outro aspecto relevante é em relação à melhoria das habitações, que se trata de uma espécie de ascensão social simbólica. Assim, reformar a casa, comprar móveis novos, por exemplo, tem uma grande importância para estas mulheres. Por isso parte do lucro é destinado a esta finalidade. 
Não obstante os avanços relatados, as mulheres destacam que as funções da esfera doméstica ainda estão a cargo delas, conforme se observa no seguinte relato: "quando eu chego em casa ainda tenho que lavar as louças e varrer a casa". Em outro relato a mulher afirma que só pode sair pra reunião à tarde depois de preparar o almoço. Isto demonstra que os traços da cultura machista ainda persistem, pois se trata de heranças culturais que persistem no cotidiano.

\section{CONCLUSÃO}

Uma breve análise da trajetória das mulheres agricultoras de Paraipaba ressalta a importância da atuação governamental junto às populações rurais. Embora estejamos analisando um caso isolado, os resultados são compatíveis com outros estudos sobre esta temática, a exemplo de Cintrão e Siliprandi (2011). Neste caso específico que tratamos aqui registramos um grande avanço, pois as trabalhadoras: são protagonistas; criaram uma associação composta 100\% (cem por cento) por mulheres; são responsáveis pela gestão, produção a nível familiar e comercialização dos produtos via Associação.

Nesse sentido, a participação destas mulheres nos Programas PAA e PNAE foi importante à medida que contribuiu para a diversificação da produção familiar e, consequentemente, a ampliação da renda familiar. Com isso, elas puderam estruturar melhor suas unidades de produção, sobretudo a partir da aquisição de utensílios industriais e reformas. Por outro lado, embora elas não tenham mencionado diretamente, a receita gerada pelo programa contribuiu para o dinamismo da economia local.

Em termos de relações de gênero e empoderamento, as mulheres se sentiram mais importantes, principalmente por dois motivos: primeiro, por terem passado a contribuir diretamente com a formação da renda familiar, sendo que em determinadas épocas do ano esta receita garante até o sustento da família; segundo, a participação no grupo possibilitou que muitas dessas mulheres, sobretudo as que fazem parte da diretoria da entidade, ocupassem os espaços púlicos do município e do território. Contudo, apesar dessas conquistas e avanços, elas destacaram que ainda Ihes cabe a execução das tarefas ditas "do lar", tais como lavar, passar, fazer as refeições, dentre outras. 
Foi possível perceber, ainda, que questões políticas e burocráticas das instituições interferem na efetividade do Programa, impossibilitando, inclusive, o cumprimento de metas. Estas relações apontaram que a autonomia dos agentes deve ser assegurada a partir da construção social de mercados.

\section{REFERÊNCIAS}

ABRAMOVAY, R. et al. Juventude e agricultura familiar: desafio dos novos padrões sucessórios. 2ed. Brasília: Edições Unesco, 1998.

O futuro das regiões rurais. Porto Alegre: Ed. UFRGS, 2003. 152p.

BERGER, P. L.; LUCKMANN, T. A Construção social da realidade: tratado de sociologia do conhecimento. Petrópolis: Vozes, 1993. 248p.

BOURDIEU, Pierre. A dominação masculina. Rio de Janeiro: Ed. Bertrand Brasil, 2003.

BRUMER, A. Gênero e agricultura: a situação da mulher na agricultura do Rio Grande do Sul. Revista Estudos Feministas Florianópolis, v .12, n. 1, p. 205-227, 2004.

BURSZTYN, Marcel. O poder dos donos: planejamento e clientelismo no Nordeste. Rio de Janeiro: Garamond; Fortaleza: BNB, 2008.

CAMARANO, A. A.; ABRAMOVAY, R. Êxodo rural, envelhecimento e masculinização no Brasil: panorama dos últimos cinqüenta anos. Rio de Janeiro: In Revista Brasileira de Estudos de População, V.15, N.2,.1998.

CARNEIRO, Maria José. Camponeses, agricultores e pluriatividade. Rio de Janeiro: Contra capa livraria, 1998.

CARVALHO, Inaiá M. M. de. O Nordeste e o regime autoritário. São Paulo: HUCITEC/SUDENE, 1987.

CORDEIRO, Rosineide (orgs) Agricultura familiar e gênero: Prática, Movimentos e Políticas Públicas. Recife: Ed. Universitária, 2006.

CASTELLS, Manuel. O Poder da Identidade. In: A Era da Informação: Economia, Sociedade e Cultura. 3. ed. São Paulo: Paz e Terra. v. 2. 1999.

DA MATTA, Roberto. A casa e a Rua: espaço, cidadania, mulher e a morte no Brasil. 5. ed. Rio de Janeiro: Zahar, 1997.

DINIZ, A. S. A construção dos perímetros irrigados e a criação de novas territorialidades no sertão. In: ELIAS, Denise \& SAMPAIO, J.L.F. (orgs) 
Paradigmas da agricultura cearense: modernização excludente. Fortaleza, CE: Edições Demócrito Rocha, 2002.

FISCHER, Isaura Rufino. O protagonismo da mulher rural no contexto da dominação. Recife: Fundação Joaquim Nabuco, Ed. Massagana, 2006.

FOUCAULT, Michel. Microfísica do poder. Rio de Janeiro: Edições Graal, 1979.

LIMA, Pedro Jorge; BELMONT, Pascoal. Para uma reflexão sobre a realidade de Paraipaba. Fortaleza. Mimeo, 1979.

MARTINS, Mônica D. Açúcar no Sertão: a ofensiva capitalista no Nordeste do Brasil. Fortaleza: Banco do Nordeste, 2008.

MENDES, Virzângela P. S.. OS PROJETOS DE VIDA DA JUVENTUDE DO PERÍMETRO CURU-PARAIPABA: entre o sonho e a realidade. Fortaleza: UECE, 2011 (Dissertação apresentada ao Programa de Pós-Graduação em Políticas Públicas $r$ Sociedade).

MENDES, Virzângela P. S.. TRAJETÓRIAS DE JOVENS DO PERÍMETRO CURUPARAIPABA: HISTÓRIAS DE RUPTURAS E CONTINUIDADES AO LONGO DE GERAÇÕES. Fortaleza: UFC, 2018 (Tese apresentada ao Programa de PósGraduação em Sociologia).

MUTONE-SMITH, D. Promover as mulheres no agronegócio é a chave para o crescimento econômico. In: TRADWINDS-Women Thrive Worldwide, 2011. Disponivel em: http://www.watradehub.com/ptt/atividades/tradewinds/jan11/promover-mulheres-no-agronegocio-e-chave-para-ocrescimento-economico. Acesso em 12 de maio de 2016.

OLIVEIRA, Priscila R. C. et al. Trabalho feminino: uma análise da inserção da mulher no mercado de trabalho em Viçosa, MG. Disponível em: $<$ http://correio.fdvmg.edu.br/downloads/SemanaAcademica2007/Anais_Artigos/Trab alho_Feminino.pdf>. Acesso em: 01 abr. 2011.

OSTERNE, Maria do Socorro Ferreira. Família, pobreza e gênero: o lugar da dominação masculina, Fortaleza, EDUECE, 2001.

SAFIOTTI, Heleieth. I. B. O poder do macho. São Paulo: Ed. Moderna, 1987.

SCOTT, Joan. Uma categoria útil para análise histórica. [S.I.]: Ed. SOS Corpo, 1991.

SCHNEIDER, Sergio (org). A Diversidade da Agricultura Familiar. 2 $2^{\mathrm{a}}$ Ed. Porto Alegre: Ed da UFRGS, 2009.

SILIPRNADI, E.; CINTRÃO, R. As mulheres agricultoras e sua participação no Programa de Aquisição de Alimentos (PAA). In: BUTTO, A.; DANTAS, I. (org.). 
Autonomia e cidadania: políticas de organização produtiva para as mulheres no meio rural. Brasília: Ministério do Desenvolvimento Agrário, 2011. P12 - 34.

VASCONCELOS, H. E. M. Descontinuidades nas dinâmicas de sucessão profissional de agricultores familiares do Projeto de Irrigação Curu Paraipaba, CE. Ceará, UFC. 2011. Tese de doutorado

WANDERLEY, Maria Nazareth. A Emergência de uma Nova Ruralidade nas Sociedades Avançadas - o rural como espaço singular e ator coletivo. Estudos Sociedade e Agricultura, n. 15, 2000. 